\title{
Specialists' View on Segregating Obstetrics and Gynecology
}

\author{
Shikha Rani ${ }^{1}$, Alka Sehgal ${ }^{2}$, Dilpreet K Pandher ${ }^{3}$, Rimpy Tandon ${ }^{4}$
}

\begin{abstract}
Background: Presently care to all women is given under the single umbrella of obstetrics and gynecology. Obstetrics is a very demanding field with unpredictable working hours and less social life. That is why over the career line many doctors leave obstetrics and go for gynecology practice. This trend has increased over the years which can affect the future workforce. Laborist model of care has been proposed to overcome this. But segregating obstetrics and gynecology can give a permanent solution to the future workforce. To evaluate this hypothesis, a survey was done to gather the opinion of obstetrics-gynecology specialists on the perceived need, benefits, and harms of separating obstetrics and gynecology. Material and methods: This was a questionnaire-based cross-sectional study conducted from September 2016 to May 2018 . Enrolled subjects were the obstetrician and gynecologists who have completed their postgraduation. A questionnaire was prepared using Google forms, keeping in view all the aspects of study. Obstetricians and gynecologists were contacted by mail, Facebook and WhatsApp groups, or in person to fill the pro forma. Stata was used to analyze the data. Mean was calculated for continuous variables and proportions for discrete variables. Analysis was performed to evaluate any relation of age, years of experience, or type of workplace from the viewpoint of segregating the branch.

Results: One hundred sixty-seven responses were received. Mean age was $39.4 \pm 10.3$ years. Thirty-seven percent had 15 years of experience in obstetrics and gynecology. Eighty-eight percent of the respondents were practicing both fields. Doctors for and against the segregation of obstetrics and gynecology were $55 \%$ and $39 \%$, respectively. Main reasons for the segregation were delivering better medical care, increased scope of subspecialization, and improved knowledge and skills of doctors. Others cited that obstetrics and gynecology are very much interrelated branches so cannot be separated. If already separated fields, 65\% (48/137) would have opted gynecology and 35\% (48/137) obstetrics. However, no difference was found in the preference for or against the segregation of medical field by age, years of experience, or the type of workplace (government/private).

Conclusion: Medical fraternity feels the need for segregating obstetrics and gynecology.

Keywords: Attitude, Observational study, Obstetric and gynecology.

Journal of South Asian Federation of Obstetrics and Gynaecology (2020): 10.5005/jp-journals-10006-1841
\end{abstract}

\section{INTRODUCTION}

Ever since the Homo sapiens came on earth, the crude form of medical care has been metamorphosing. This has led to evolution of the present modern medical era. Better understanding of human anatomy and physiology and ever-transforming technology had led to the development of various new medical fields. Obstetrics and gynecology have also been witnessed to varied modifications. Before the 18th century, obstetrics was not recognized as a specialty. Care of birthing women and delivery were the arenas of midwives. ${ }^{1}$ Gynecological problems were dealt by the surgeons. ${ }^{2}$ About a century ago, Dr. Reuben Peterson proposed to combine obstetrics and gynecology to provide all care to women under a single umbrella. ${ }^{3}$ Over the years, various factors have led to the development of subspecialization in medical areas. These factors are an advent of newer technologies, more complex subjects, growing population and its need, personal and professional interest, and better recognition in the medical community. Obstetrics and gynecology too have witnessed subspecialization. Many investigators studied the impact of subspecialization on the medical professionals and the society. ${ }^{4,5}$

Obstetrics requires an unending effort from the doctor due to its unpredictable working environment and complications, intensive intrapartum monitoring, and medicolegal issues. This leads to less social interaction, professional dissatisfaction, and early burnout among doctors. Due to which, doctors leave obstetrics practice very early, now choosing for a less-stressful gynecological subspecialization. ${ }^{6}$ Subspecialization is booting the shortage of obstetricians. ${ }^{5}$ In 2005, a Royal College of Obstetricians
${ }^{1-4}$ Department of Obstetrics and Gynecology, Government Medical College and Hospital, Chandigarh, India

Corresponding Author: Shikha Rani, Department of Obstetrics and Gynecology, Government Medical College and Hospital, Chandigarh, India, Phone: +91 9646040559, e-mail: shikhataneja2000@yahoo. co.in

How to cite this article: Rani S, Sehgal A, Pandher DK, et al. Specialists' View on Segregating Obstetrics and Gynecology. J South Asian Feder Obst Gynae 2020;12(6):387-390.

Source of support: Nil

Conflict of interest: None

and Gynecologists (RCOG) consultation document discussed the future role of consultants in obstetrics and gynecology. They acknowledged that the biggest challenge is the balance between obstetrics and gynecology. The authors said it is beyond their capacity to discuss if the specialty should divide. ${ }^{7}$

In developing countries to reduce maternal morbidity and mortality, various programs have been started for free institutional deliveries without enhancing the existing medical infrastructure. This has led to clustering of emergency obstetrics in government institutes. Coping with all the added burden had led to the stasis of gynecology in government institutes.

Keeping the health system in developing countries, available health professional workforce, cost of medical care, and changing paradigm of practice in obstetrics and gynecology, we think that segregating obstetrics and gynecology can better meet

( ) Jaypee Brothers Medical Publishers. 2020 Open Access This article is distributed under the terms of the Creative Commons Attribution 4.0 International License (https://creativecommons.org/licenses/by-nc/4.0/), which permits unrestricted use, distribution, and non-commercial reproduction in any medium, provided you give appropriate credit to the original author(s) and the source, provide a link to the Creative Commons license, and indicate if changes were made. The Creative Commons Public Domain Dedication waiver (http://creativecommons.org/publicdomain/zero/1.0/) applies to the data made available in this article, unless otherwise stated. 
the demands of our medical fraternity and society, as this may lead to improved doctor-patient ratio, especially in rural areas, better personal and professional satisfaction among medical professionals, and decreased healthcare cost. With this, a hypothesis study was planned to evaluate the opinion of obstetric-gynecology specialists on the perceived need, benefits, and harms of separating obstetrics and gynecology.

\section{Material and Methods}

This was a questionnaire-based cross-sectional study. Study period was from September 2016, to May 2018. The study had been approved by the institutional review board. Enrolled subjects were the obstetricians and gynecologists who have completed their postgraduation. A questionnaire was prepared using Google forms and on the basis of previous studies done. The questionnaire had both open- and close-ended questions. However, adaptive questioning or randomization of the question was not done. It was a closed survey which was circulated by email, Facebook, and WhatsApp web. The survey was not posted on any website but a link was provided to the eligible subjects through social media and email. No advertisement for the survey was done. A consent form was incorporated in the survey only. The participation was totally on a voluntary basis and no incentive was given to the participants.

Eligible subjects were given a serial number. They were asked about their demographic profile, workplace, type of work, and area of interest. Subjects were asked about their viewpoint on whether obstetrics or gynecology should be separate branches and the reason for their choice. All the information was entered by the participants themselves only. Personal information of the participants was protected as the Google form was password protected.

Certain questions were compulsory and to be completed before the final submission of the survey, else the survey would not be submitted. Participants were not able to review their responses once submitted. No minimum duration was kept for filling the survey. Primary investigator kept a check on multiple entries. In case of multiple entries, the first entry was used in the final analysis.

\section{Statistical Analysis}

Sample size or participation rate could not be calculated as social media was used for the survey. All data were compiled into Google sheet. Stata was used to analyze the data. Mean was calculated for continuous variables and proportions for discrete variables. Chisquare test and student's $t$-test were done to evaluate the effect of age, years of experience, and workplace on the opinion of whether segregation should be done or not. No other method was used to adjust for the nonrepresentative sample.

\section{RESULTS}

We are reporting a questionnaire-based study on belief of medical professionals about the benefits and harms of segregating obstetrics and gynecology. During the study period, 167 responses were received. Baseline characteristics were shown in Table 1.

Table 2 shows the subject response on their present type of medical care services and working style.

Ninety-two (55\%) were for and sixty-five (39\%) were against the opinion regarding segregating obstetrics and gynecology. Ten $(6 \%)$ of the respondents were undecided about whether it should be done or not.
Table 1: Baseline characteristics of respondents

\begin{tabular}{|c|c|}
\hline Variables & Number of responses $(n=167)$ \\
\hline Age (year) ${ }^{\mathrm{a}}$ & $39.4 \pm 10.3$ \\
\hline Female $^{b}$ & $143(86 \%)$ \\
\hline \multicolumn{2}{|l|}{ Qualification $^{b}$} \\
\hline - MBBS & $8(5.3 \%)$ \\
\hline - $\quad \mathrm{DGO}$ & $9(5.4 \%)$ \\
\hline - DNB & $15(9 \%)$ \\
\hline - $\mathrm{MD} / \mathrm{MS}$ & $135(80.3 \%)$ \\
\hline \multicolumn{2}{|l|}{ Years of experience ${ }^{b}$} \\
\hline - $<5$ & $62(37 \%)$ \\
\hline - $5-10$ & $26(15 \%)$ \\
\hline - $11-15$ & 31 (19\%) \\
\hline - $16-20$ & $18(11 \%)$ \\
\hline - $>20$ & $30(18 \%)$ \\
\hline \multicolumn{2}{|l|}{ Workplace $^{\mathrm{b}}$} \\
\hline - Medical college & $88(52.6 \%)$ \\
\hline - Government hospitals & $20(11.9 \%)$ \\
\hline - Private hospitals & $59(35.3 \%)$ \\
\hline \multicolumn{2}{|l|}{ Designation $^{\mathrm{b}}$} \\
\hline - Senior resident & $62(37 \%)$ \\
\hline - Assistant professor & $6(4 \%)$ \\
\hline - Associate professor & $12(7 \%)$ \\
\hline - Professor & $15(9 \%)$ \\
\hline - Consultant & $72(43 \%)$ \\
\hline
\end{tabular}

Table 2: Present working style and contribution to obstetrics and gynecology

\begin{tabular}{lc}
\hline Variable & Number of responses $(n=167)$ \\
\hline Presently practicing $^{\text {a }}$ & \\
• Only obstetrics & $5(3 \%)$ \\
• Only gynecology & $15(9 \%)$ \\
• Both & $147(88 \%)$ \\
Emergency obstetrics practice $^{b}$ & $47.4 \pm 26.5 \%$ \\
Gynecology practice $^{\mathrm{b}}$ & $26.8 \pm 24.1 \%$ \\
Research $^{\mathrm{b}}$ & $13 \pm 14.56 \%$ \\
Nature of academics $^{\mathrm{a}}$ & \\
• Obstetrics only & $21(12.6 \%)$ \\
• Gynecology only & $26(15.6 \%)$ \\
• Both & $120(71.9 \%)$ \\
Want personal improvement in & \\
• Obstetrics & $12(7.2 \%)$ \\
• Gynecology & $71(42.5 \%)$ \\
• Both & $84(50.3 \%)$ \\
\hline
\end{tabular}

${ }^{\mathrm{a}}$ Represent number (percentage), ${ }^{\mathrm{b}}$ Represent mean $\pm \mathrm{SD}$

Hundred (62\%) think that it will benefit both urban and rural population. Fifty-four (33.3\%) and thirteen (4.9\%) believe that this segregation will help only urban and only rural population, respectively. One hundred thirty-seven subjects answered the question, "If obstetrics and gynecology already separated which one they have chosen?" Eighty-nine (65\%) replied that they would have opted gynecology and forty-eight (35\%) would have opted obstetrics. The reasons for and against the choice were shown in Figures 1 and 2, respectively.

No significant difference was found in the preference for or against the segregation of medical field by age ( $p$-value 0.36 ), years 
of experience ( $p$-value 0.22 ), or the type of workplace (government/ private).

Various suggestions were given by the enrolled subjects about how the segregation is to be done. These are either at postgraduation level, after postgraduation in the form of subspecialization, or three years postgraduation to be divided in the first one year of basic education in both obstetrics and gynecology and further 2 years are to be segregated.

\section{Discussion}

The present study found that medical fraternity has started feeling the need of segregating obstetrics and gynecology. More dialog is required on how and when this segregation is to be done. After embracing subspecialization in obstetrics and gynecology, many studies were done to evaluate its impact. Zuspan et al. did a questionnaire-based study to evaluate the impact of subspecialties on obstetrics and gynecology. Six hundred eighty-five responses were received, among which $92 \%$ agreed that subspecialties had led to the development of the field. Eighty-eight percent were of the opinion that it had improved the image of obstetrician and gynecologists in the medical school. Seventy-three percent and

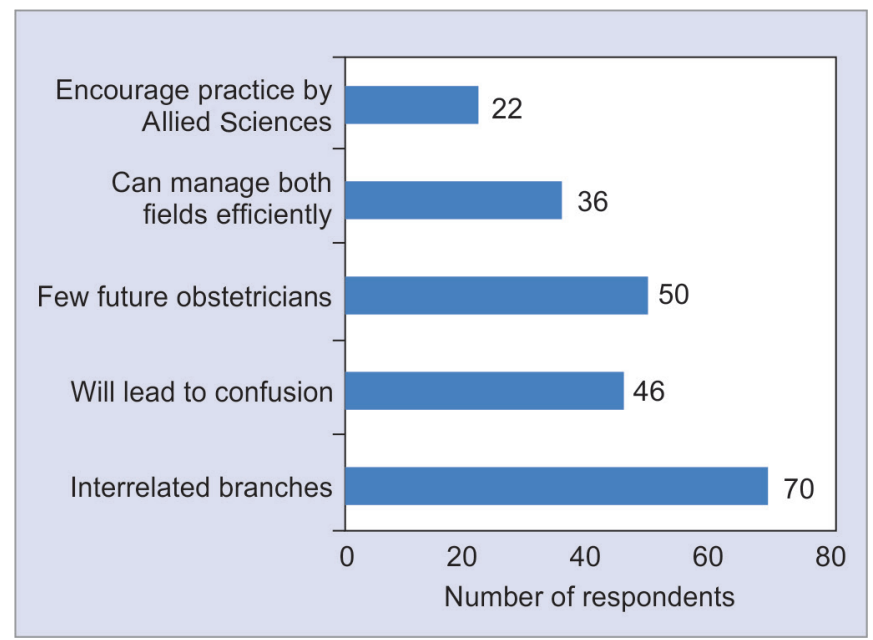

Fig. 1: Reasons for not segregating obstetrics and gynecology eighty-six percent opined that it leads to better education of medical students and residents. Eighty-two percent supported the development of subspecialties. ${ }^{8}$

Ludwig did a review of the pros and cons of subspecialties in obstetrics and gynecology. He had mentioned that in developing countries with pyramidal medical training it is futile to go for subspecialization. As the education will be more expensive, time consuming and extra years spent before subspecialty has little or nothing to do with the clinical scenario of that subspecialty. The medical hierarchies will bring more expectations, lesser opportunities in the future, more urbanization of medical personnel, and dearth of generalists in the future. Subspecialization will increase the cost of treatment as the patient has to seek treatment from a different subspecialist and also the government has to pay different subspecialist. However, keeping the field integrity will provide primary preventive care to women under one roof. ${ }^{9}$

Decades after researchers analyzed the impact of obstetrics and gynecology on the lives of medical professionals and choosing it as a career. Jackson et al. during the career advice of medical trainees found that final year trainees did not want to opt for obstetrics and gynecology due to competition issues, working hours, and training issues. Obstetrics and gynecology was the second most common field rejected by trainees following surgery. They reported that work-life balance and flexible work opportunities were important factors influencing the choice of specialist career. ${ }^{6}$

Pandey et al. did a questionnaire-based study among the trainees of obstetrics and gynecology to determine their views on segregating obstetrics and gynecology. Seventy-three responses were collected. Thirty-one participants wanted to practice only gynecology, twenty-one only obstetrics, seventeen both obstetrics and gynecology, and five were not sure about their stream. The participants gave various reasons for practicing only gynecology, like better job satisfaction, less litigation, and operating better social life. The most common reasons cited for practicing only obstetrics were more challenging, more rewarding, and unpredictable. Seventy percent of participants opined that the specialties to be splitted..$^{10}$ In our study, 92 (55\%) doctors wanted segregation of the specialty. Sixty-five percent of respondents will opt for gynecology if the field is segregated.

National Health Service confederation did a survey in 2004 on the type of maternity care in England and Wales. They found that

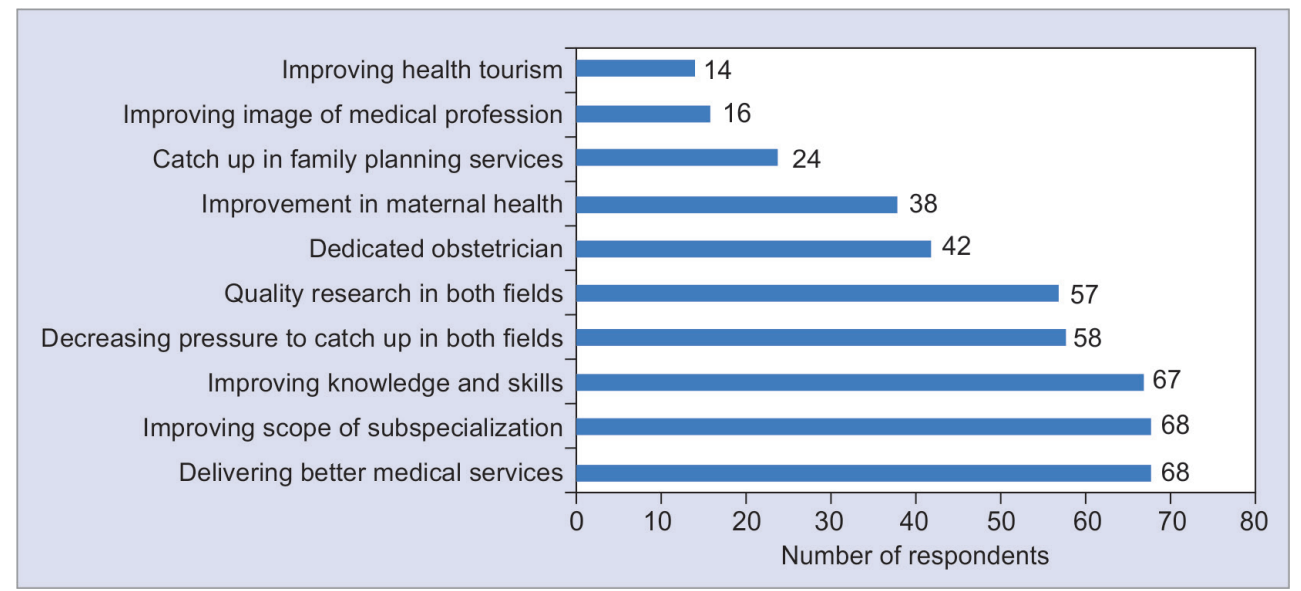

Fig. 2: Reasons for segregating obstetrics and gynecology 
$77 \%$ practice both obstetrics and gynecology, $15 \%$ only gynecology, and $8 \%$ only obstetrics. But over the years trainees were more inclined that the specialty should be segregated. This had been reflected in the RCOG survey and the trend was like 15\% (1995), $24 \%$ (1997), and 34\% (2003). ${ }^{11}$ In our study, $95 \%$ of the respondents are practicing both obstetrics and gynecology and only $5 \%$ are practicing only gynecology. But emergency obstetrics practice had wide variation.

Currently in the United Kingdom, 20\% of doctors who join the specialist training in obstetrics and gynecology are leaving it even before their completion. ${ }^{12}$ Goldacre et al. surveyed 27,967 doctors after completion of postgraduation. They found that $19 \%$ of the doctors changed their career or specialty over a 5-year period. This change had remained fairly constant from 1977 to 1996 despite changes in the training programs and the opportunities. ${ }^{13}$ Gafson et al. did a survey of 183 trainees to evaluate the attitude of the trainees toward attrition in obstetrics and gynecology. Twentythree percent of respondents had considered leaving the specialty. This attrition can impact on workforce planning, patient outcome, and physicians' well-being. They concluded that further steps are to be taken to make changes in the present postgraduate training. ${ }^{14}$

To overcome this attrition, a laborist model has been introduced in a few developed countries. Laborist is an alternative career option in the field of obstetrics and gynecology first proposed by Dr. Louis Weinstein. ${ }^{15}$ Laborist is traditionally an obstetrics and gynecology physician who is employed by the hospital to manage laboring patients and obstetric emergencies. ${ }^{16}$ Laborist model is believed to improve inpatient outcome, reduce medical liability, provide satisfaction, and reduce burnout. ${ }^{15}$

Iriye BK reviewed the impact of obstetrician and gynecologist hospitalists on the quality of obstetric care. He reported that there was a decrease in overall cesarean delivery rates, improved trial of labor after cesarean delivery, decrease in adverse neonatal events and also a cost-effective solution to the coverage of labor and delivery unit. ${ }^{17}$

American College of Obstetrics and Gynecology (2016) too has supported the development of obstetrics and gynecologic hospitalist model. There are definite advantages for adapting this hospitalist model. However, further research is required to determine the effect of this model on improved patient outcome and economic feasibility. ${ }^{18}$

Every successful program reaches an inflection point and obstetrics and gynecology too has reached the same. We believe that laborist model is almost like segregating obstetrics and gynecology. Changes must be made now for further development in the field and to meet the future demands as what worked before will not work now and also what worked for the developed countries may not necessarily work for the developing ones. Developing countries must realize that their medical system is totally different from the developed countries. So, to prevent the shortage of future obstetricians, it will be prudent to segregate obstetrics and gynecology.

This is the first such study done in India and due to a web-based questionnaire wide geographical areas covered are the strength of our study, though the study has limitations due to its small sample size and no representation of policy makers.

\section{Conclusion}

Medical fraternity feels the need of segregating obstetrics and gynecology. Valid arguments have been suggested in favor and against. But, still there is a need for more dialogs to decide the future of obstetrics and gynecology.

\section{References}

1. Gelis J. History of childbirth. Boston: Northeastern University Press; 1991, pp. 96-98.

2. Bynum WF, Porter R (eds.) Companion encyclopedia of the history of medicine. London and New York: Routledge; 1993, pp. 1050-1052.

3. Peterson R. The future of obstetrics and gynecology as a specialty. JAMA 1920;74:1361-1364. DOI: 10.1001/jama.1920.02620200001001.

4. Merrill J. (Sub)specialization in obstetrics and gynecology: results of a survey by The American Board of Obstetrics and Gynecology. Am J Obstet Gynecol 1987;156:550-558. DOI: 10.1016/0002-9378(87)90048-2.

5. Rayburn WF, Gant NF, Gilstrap LC, et al. Pursuit of accredited subspecialties by graduating residents in obstetrics and gynecology, 2000-2012. Obstet Gynecol 2012;120:619-625. DOI: 10.1097/ AOG.0b013e318265ab0a.

6. Jackson C, Ball JE, Hirsh W, et al. Informing choices: the need for career advice in medical training. Cambridge/Birmingham: National Institute for Careers Education and Counselling; 2002. Retrieved on January 9, 2018. Available from: http://www.crac.org.uk/CMS/files/upload/ nicec_informingchoices_medicaltrainig_report

7. Royal College of Obstetricians and Gynaecologists. London. The future role of the consultant: A working party report. Retrieved on January 8, 2018. Available from: https://www.rcog.org.uk/en/ guidelines-research-services/guidelines/the-future-role-of-theconsultant

8. Zuspan FP, Sachs L. The impact of subspecialties on obstetrics and gynecology. Am J Obstet Gynecol 1988;158:747-753. DOI: 10.1016/0002-9378(88)90067-1.

9. Ludwig H. Subspecialization in gynecology and obstetrics: advantages and disadvantages. Eur J Obstet Gynecol Reprod Biol 1991;41:31-35. DOI: 10.1016/0028-2243(91)90316-d.

10. Pandey U, Lindow S. Should obstetrics and gynaecology be separate specialities? A survey of Yorkshire trainees. J Obstet Gynaecol 2006;26:305-306. DOI: 10.1080/01443610600594807.

11. NHS Confederation. Survey of models of maternity care. London: The NHS Confederation; 2004.

12. Royal College of Obstetricians and Gynecologists statement: imposition of junior doctor's contract. Retrieved on January 11 2018. Available from: www.rcog.org.uk/en/news/rcogstatementimposition-of-junior-doctors-contract

13. Goldacre MJ, Laxton L, Lambert TW. Medical graduates' early career choices of specialty and their eventual specialty destinations: UK prospective cohort studies. BMJ 2010;341:c3199. DOI: 10.1136/bmj. c3199.

14. Gafson I, Currie J, O'Dwyer S, et al. Attitudes towards attrition among UK trainees in obstetrics and gynaecology. Br J Hosp Med 2017;78:344-348. DOI: 10.12968/hmed.2017.78.6.344.

15. Weinstein $L$. The laborist: a new focus of practice for the obstetrician. Am J Obstet Gynecol 2003;188:310-312. DOI: 10.1067/mob.2003.133.

16. Srinivas SK, Lorch SA. The laborist model of obstetric care: we need more evidence. Am J Obstet Gynecol 2012;207:30-35. DOI: 10.1016/j. ajog.2011.10.009.

17. Iriye BK. Impact of obstetrician/gynecologist hospitalists on quality of obstetric care (cesarean delivery rates, trial of labor after cesarean/ vaginal birth after cesarean rates, and neonatal adverse events). Obstet Gynecol Clin North Am 2015;42:477-485. DOI: 10.1016/j. ogc.2015.05.006

18. American College of Obstetricians and Gynecologists' Committee on Patient Safety and Quality Improvement; American College of Obstetricians and Gynecologists' Committee on Obstetric Practice. Committee Opinion No. 657 summary: the obstetric and gynecologic hospitalist. Obstet Gynecol 2016;127:419. DOI: 10.1097/ AOG.0000000000001310 